\title{
Twelve-Year History of STEMI Management in Tehran Heart Center: Concomitant Reduction of In-Hospital Mortality and Hospitalization Length
}

\author{
Seyedmohammad Saadatagah, MD'; Saeed Ghodsi, MD'; Negar Omidi, MD'; Hamidreza Poorhosseini, MD'; Mojtaba Salarifar, MD; Saead \\ Sadeghian, MD'; Mohammad Alidoosti, MD'; Seyed Ebrahim Kassaian, MD'; Hassan Aghajani, MD'; Seyedeh Hamideh Mortazavi, MD \\ $\mathrm{MPH}^{1}$; Kaveh Hosseini, MD MPH${ }^{1}$; Babak Geraiely, $\mathrm{MD}^{{ }^{*}}$
}

'Tehran Heart Center (THC), Tehran University of Medical Sciences, Tehran, Iran

\begin{abstract}
Background: Cardiovascular-related death remains the major cause of mortality in Iran despite significant improvements in its care. In the present study, we report the in-hospital mortality, hospitalization length, and treatment methods for patients with STelevation myocardial infarction (STEMI) in Tehran Heart Center (THC).

Methods: Records pertaining to patients with STEMI from March 2006 to March 2017 were extracted from the databases of THC. Besides a description of temporal trends, multivariable regression analysis was used to find factors associated with in-hospital mortality.

Results: During the study period, 8,295 patients were admitted with STEMI with a mean age of $60.4 \pm 12.5$ years. Men accounted for $77.5 \%$ of the study population. Hospitalization length declined from 8.4 to 5.2 days, and in-hospital mortality was reduced from $8.0 \%$ to $3.9 \%$ (both $P$ values $<0.001$ ). In a multivariable model adjusted for age, sex, conventional cardiac risk factors, prior cardiac history, and indices of event severity, primary percutaneous coronary intervention (PCI) $(\mathrm{OR}: 0.280,95 \% \mathrm{Cl}: 0.186$ to $0.512 ; P<0.001$ ), coronary artery bypass graft $(\mathrm{CABG})$ surgery (OR: $0.482,95 \% \mathrm{Cl}: 0.220$ to $0.903 ; P=0.025$ ), and rescue or facilitated $\mathrm{PCI}$ (OR: $0.420,95 \% \mathrm{Cl}: 0.071$ to $0.812 ; P=0.001)$ were all associated with reduced in-hospital mortality in comparison with medical treatment. Furthermore, primary $\mathrm{PCI}$ was a crucial protective factor against prolonged length of hospital stay (OR: $0.307,95 \% \mathrm{Cl}: 0.266$ to $0.594 ; P<0.001)$.

Conclusion: In-hospital mortality and hospitalization length were almost halved during the study period, and primary PCI has now replaced thrombolysis in the management of STEMI.

Keywords: Coronary artery disease, Fibrinolytic agents, Hospital mortality, Percutaneous coronary intervention, Reperfusion; STelevation myocardial infarction

Cite this article as: Saadatagah S, Ghodsi S, Omidi N, Poorhosseini H, Salarifar M, Sadeghian S, et al. Twelve-year history of STEMI management in Tehran Heart Center: concomitant reduction of in-hospital mortality and hospitalization length. Arch Iran Med. 2020;23(8):514-521. doi: 10.34172/aim.2020.53.
\end{abstract}

Received: May 8, 2019, Accepted: June 2, 2020, ePublished: August 1, 2020

\section{Introduction}

Cardiovascular death remains the major cause of death in Iran $^{1,2}$ and one of the cardinal issues in policymaking. ${ }^{3}$ STelevation myocardial infarction (STEMI) management is one of the key components of acute cardiovascular care. Given its high burden, many operational and research plans are currently performed in this field. ${ }^{4-7}$ Developed countries have devised a comprehensive program for the management of patients with STEMI, resulting in successful replacement of thrombolytic drugs with primary percutaneous coronary intervention (P-PCI). ${ }^{8,9}$

A comprehensive STEMI management program has been commenced in Iran recently. This national program aims to provide P-PCI all around the country in a wellconcerted geographic coverage in a 24/7 fashion. All aspects of STEMI management including dispatch center, on-site electrocardiogram (ECG), electronic ECG transfer system, transportation plan, and P-PCI team activation before the ambulance arrival are incorporated in this program. However, reports are still lacking on the success of this program.

In the present study, we report the frequency and temporal trend of STEMI patients, as well as its annual distribution, in-hospital mortality, hospitalization length, and treatment methods between March 2006 and March 2017 in Tehran Heart Center (THC).

\section{Materials and Methods}

Study Design

The present study enrolled patients admitted into THC between March 2006 and March 2017 with STEMI diagnosis, whether or not they were initially admitted into THC or were transferred from another center. For each admitted patient, questionnaires comprising detailed 
information on demographic characteristics, risk factors, past medical history, paraclinical findings, ischemic heart disease presentation, and treatment were filled in by welltrained nurses. The obtained data, in combination with follow-up information and additional electronic health records, were combined to set up the ischemic heart disease databank of THC, which presently contains data on more than 120000 patients.

\section{Definitions}

STEMI was defined as the presence of more than a 1-mm ST-segment elevation in two contiguous ECG leads persisting for more than 20 minutes and accompanied by acute symptoms. Along with self-reports about previously diagnosed diseases necessitating medical treatment, diabetes mellitus was defined as a fasting blood glucose level of $126 \mathrm{mg} / \mathrm{dL}$ or greater and/or an HbA1C level of greater than $7 \% \mathrm{mmol} / \mathrm{mol}$. Hypertension was defined as the current consumption of antihypertensive drugs or at least two blood pressure measurements of 140/90 mm Hg or greater after the acute phase. Dyslipidemia was defined as a high-density lipoprotein cholesterol level of less than $40 \mathrm{mg} / \mathrm{dL}$ in men and less than $50 \mathrm{mg} / \mathrm{dL}$ in women, a triglyceride level of greater than $150 \mathrm{mg} / \mathrm{dL}$, and a total cholesterol level of more than $200 \mathrm{mg} / \mathrm{dL}$. Chronic kidney disease was defined as a glomerular filtration rate of less than $60 \mathrm{~mL} / \mathrm{min}$. Peripheral artery disease was defined as an ankle-brachial index of less than 0.9 or previous revascularization of peripheral arteries. Patients who left the hospital alive were considered the discharged group and those who died during hospitalization were considered the deceased group. For the discharged group, hospitalization length was calculated by subtracting the admission date from the discharge date; and for the deceased group, the expiration date was considered the end of hospitalization. STEMI complications were considered to be ventricular septal defects, free wall rupture and tamponade, advanced atrioventricular block (second or third degree), acute mitral regurgitation, and ventricular tachycardia/fibrillation. A current smoker was defined as a patient having ever smoked more than 100 cigarettes with a concomitant history of smoking over the preceding month. A family history of early coronary artery disease (CAD) was defined as diagnosed CAD in first-degree relatives before 55 in men and 65 in women.

The patients were divided into five groups based on the reperfusion strategy adopted for them: 1) the medical treatment group: if no reperfusion strategy was used in the first 24 hours following STEMI; 2) the thrombolytic group: if a thrombolytic agent was used as the first treatment and there was no PCI during the first 24-hour post STEMI period; 3) the rescue or facilitated (R/F) PCI group: if PCI was performed in patient who had received thrombolytic within 24 hours after STEMI; 4) the P-PCI group: if P-PCI was performed as the initial strategy for reperfusion; and 5) the coronary artery bypass graft (CABG) group: if this surgical modality constituted the initial strategy for reperfusion.

\section{Statistical Analysis}

The dichotomous variables were presented as numbers (percentages) and the continuous variables as mean \pm the standard deviation for those with normal distributions, and as median (interquartile ranges [IQRs]) for those without normal distributions. Group comparisons for the categorical and continuous variables were performed using the $\chi^{2}$ test, the Mann-Whitney test, or the $t$-test, as appropriate. A $P$ value of less than 0.05 was considered statistically significant. Logistic regression was applied to calculate the crude and adjusted effects of each variable on the outcome of interest. Hospitalization length was expressed as both the median (IQRs) and the 5\% trimmed mean with relatively equal manners and identical results. In a further multiple regression analysis, the cutoff point of 5 days (overall median) was used to differentiate between prolonged and short hospitalization lengths. All variables were tested in univariate analysis and those with a $P$ value of less than 0.2 were included in the final multivariate binary logistic regression. Enter and backward stepwise methods in the regression were utilized to find adjusted significant associations. The final step is shown to avoid data overload.

\section{Results}

From 2006 to 2017, a total of 8295 patients were hospitalized in THC with a STEMI diagnosis. The mean age of the study population was $60.4 \pm 12.5$ years, and men represented $77.5 \%$ of the entire study subjects. The basic demographic and clinical features of all the patients are presented in Table 1. As shown in Figure 1, the biannual number of the admitted patients during these years increased from 1,214 in the period of 2006-2008 to 1,506 in the period of 2015-2017 $(P=0.018)$. Despite some differences between various months of the year, there was no statistically significant difference in the number of hospitalization cases per month $(P=0.342)$. Almost half of the patients (48.7\%) had arrived between 9 am to $4 \mathrm{pm}$ (an 8-hour period), while the rest of them (51.3\%) had arrived between $5 \mathrm{pm}$ and 8 am (a 16-hour period).

Of the 8,295 patients, 7,852 (94.6\%) patients were discharged and $443(5.4 \%)$ died in the hospital. As demonstrated in Table 1, the comparison between the expired patients and the discharged patients using the univariate analysis indicated that the deceased patients were older $(69.5 \pm 12.1$ years vs $59.9 \pm 12.4$ years; $P<$ $0.001)$, more frequently hypertensive $(54.1 \%$ vs $42.8 \%$; $P$ $<0.001)$, and more frequently diabetic ( $42.1 \%$ vs $29.4 \%$; $P<0.001)$. While $77.0 \%$ of the deceased group did not receive any reperfusion treatment, only $6.7 \%$ in the discharged group did not receive it $(P<0.001)$. 
Table 1. Baseline Clinical Characteristics of the Study Population $(\mathrm{N}=8295)$

\begin{tabular}{|c|c|c|c|c|}
\hline & $\begin{array}{l}\text { Discharged } \\
(\mathrm{n}=7852)\end{array}$ & $\begin{array}{l}\text { Deceased } \\
(n=443)\end{array}$ & $\begin{array}{c}\text { Total } \\
(\mathrm{n}=\mathbf{8 2 9 5})\end{array}$ & $P^{*}$ \\
\hline Age (y) & $59.9 \pm 12.4$ & $69.5 \pm 12.1$ & $60.4 \pm 12.5$ & $<0.001$ \\
\hline Men & $78.2 \%(6140)$ & $65.9 \%(292)$ & $77.5 \%(6432)$ & $<0.001$ \\
\hline Hypertension & $42.8 \%(3361)$ & $54.1 \%(240)$ & $43.4 \%(3601)$ & $<0.001$ \\
\hline Diabetes & $29.4 \%(2308)$ & $42.1 \%(187)$ & $30.1 \%(2495)$ & $<0.001$ \\
\hline Hyperlipidemia & $39.4 \%$ (3094) & $37.5 \%(166)$ & $39.3 \%(3260)$ & 0.435 \\
\hline Family history of CAD & $11.8 \%(927)$ & $3.3 \%(15)$ & $11.4 \%(942)$ & $<0.001$ \\
\hline \multicolumn{5}{|l|}{ Smoking } \\
\hline Current & $35.5 \%(2787)$ & $21.4 \%(95)$ & $34.7 \%(2882)$ & $<0.001$ \\
\hline Former & $8.2 \%(644)$ & $4.8 \%(21)$ & $8.0 \%(665)$ & 0.021 \\
\hline \multicolumn{5}{|l|}{ Opium } \\
\hline Current & $12.5 \%(982)$ & $8.8 \%(39)$ & $12.4 \%(1021)$ & 0.032 \\
\hline Former & $2.2 \%(173)$ & $0.7 \%(3)$ & $2.1 \%(176)$ & 0.018 \\
\hline Hospitalization length & $6(4-8)$ & $3(1-7)$ & $5(4-8)$ & $<0.001$ \\
\hline \multicolumn{5}{|l|}{ History of } \\
\hline CABG & $5.0 \%(393)$ & $5.7 \%(25)$ & $5.1 \%(418)$ & 0.553 \\
\hline $\mathrm{CHF}$ & $1.6 \%(126)$ & $8.0 \%(35)$ & $1.9 \%(161)$ & $<0.001$ \\
\hline PAD & $0.6 \%(47)$ & $0.9 \%(4)$ & $0.6 \%(51)$ & 0.374 \\
\hline CKD & $2.7 \%(212)$ & $13.9 \%(62)$ & $3.3 \%(274)$ & $<0.001$ \\
\hline COPD & $1.2 \%(94)$ & $1.4 \%(6)$ & $1.2 \%(100)$ & 0.780 \\
\hline Ejection fraction (\%) & $40.5 \pm 9.5$ & $28.9 \pm 10.7$ & $39.9 \pm 9.84$ & $<0.001$ \\
\hline \multicolumn{5}{|l|}{ Complication } \\
\hline VSD & $0.1 \%(8)$ & $2.3 \%(10)$ & $0.2 \%(18)$ & $<0.001$ \\
\hline VT/VF & $2.0 \%(157)$ & $30.5 \%(135)$ & $3.5 \%(292)$ & $<0.001$ \\
\hline AV block & $0.8 \%(63)$ & $4.5 \%(20)$ & $1.0 \%(83)$ & $<0.001$ \\
\hline \multicolumn{5}{|l|}{ Treatment } \\
\hline Medical treatment & $6.7 \%(526)$ & $77.0 \%(341)$ & $10.5 \%(867)$ & $<0.001$ \\
\hline Thrombolytic & $38.5 \%(3023)$ & $3.2 \%(14)$ & $36.6 \%(3037)$ & $<0.001$ \\
\hline $\mathrm{R} / \mathrm{F} \mathrm{PCl}$ & $22.2 \%(1743)$ & $3.4 \%(15)$ & $21.2 \%(1758)$ & $<0.001$ \\
\hline Primary $\mathrm{PCl}$ & $28.8 \%(2261)$ & $14.0 \%(62)$ & $28.0 \%(2323)$ & $<0.001$ \\
\hline CABG & $3.8 \%(298)$ & $2.4 \%(10)$ & $3.7 \%(308)$ & 0.098 \\
\hline
\end{tabular}

AV, Atrioventricular; CABG, Coronary artery bypass graft; CAD, Coronary artery disease; CHF, Congestive heart failure; CKD, Chronic kidney disease; COPD, Chronic obstructive pulmonary disease; PAD, Peripheral artery disease; PCI, Percutaneous coronary intervention; R/F, Rescue or facilitated; VSD, Ventricular septal defect; VT/VF, Ventricular tachycardia/fibrillation. ${ }^{*} P$ value of univariate analysis by adjusted $x 2$ for the categorical parameters or the Student t-test for the continuous variables.

During the mentioned period, along with a decline in the mean length of hospital stay (from 8.4 to 5.2 days; $P$ $<0.001$ ), in-hospital mortality also decreased significantly (from $8.0 \%$ to $3.9 \%$ ). The age-stratified plots of in-hospital mortality and hospital stay are illustrated in Figures 2 and 3, respectively. The temporal trend of the treatment strategies is presented in Figure 4. Twelve years prior to the writing of this article, pharmacologic thrombolysis was the main reperfusion strategy in the majority of cases insofar as $72.3 \%$ of the cases received this treatment and only 7.2\% cases underwent P-PCI. The period of 20062017 witnessed a significant reduction in thrombolytic use (declined to $16.5 \%$ ) and a rise in P-PCI (up to $58.6 \%, P$ for trend $<0.001)$. It should be noted that the $24 / 7 \mathrm{P}-\mathrm{PCI}$ strategy in accordance with the 24/7 national program was established in THC in September 2015, since which time all patients with STEMI having arrived at our center in a timely fashion have been treated with P-PCI. Accordingly, all the patients who received thrombolytic treatment after this time were those initially treated in another center before referral to THC.

In the multivariable binary logistic regression model, in comparison with medical treatment, P-PCI (OR: 0.280 , $95 \%$ CI: 0.186 to $0.512 ; P<0.001$ ), CABG (OR: 0.482 , $95 \%$ CI: 0.220 to $0.903 ; P=0.025)$, and $\mathrm{R} / \mathrm{F}$ PCI (OR: $0.420,95 \% \mathrm{CI}: 0.071$ to $0.812 ; P<0.001$ ) were associated with reduced in-hospital mortality. All other statistically significant variables and a complete list of variables included in the model are presented in Table 2. Furthermore, primary PCI was a crucial protective factor against prolonged length of hospital stay (OR: 0.307, 95\% CI: 0.266 to $0.594 ; P<0.001)$. 

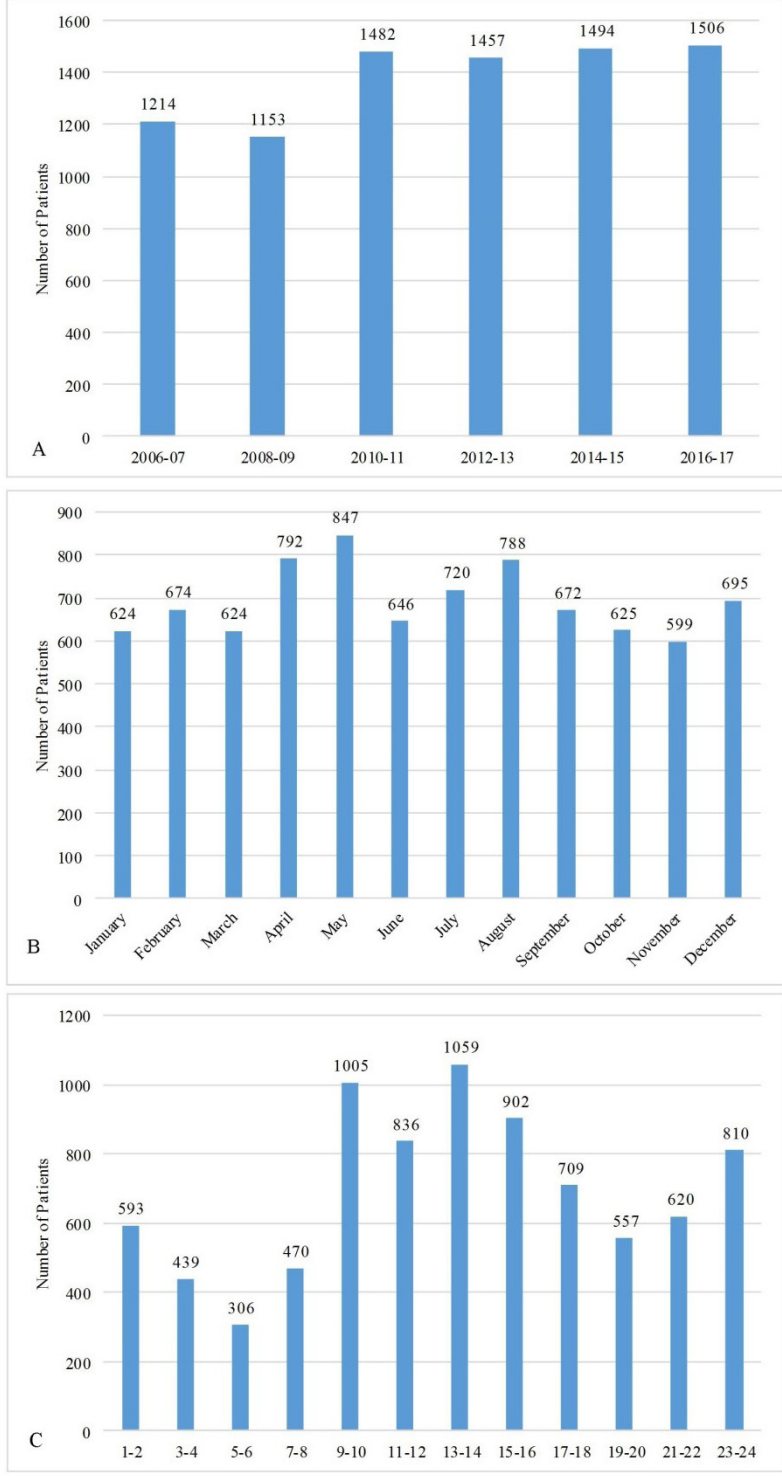

Figure 1. A) Biannual, B) Monthly, and C) Daily Distributions of Patients with STEMI from 2006 to 2017.

\section{Discussion}

By studying 8,295 patients with STEMI hospitalized in THC between March 2006 and March 2017, we presented the annual number of such patients and their time distribution. This time period saw a concomitant decline in terms of in-hospital mortality (from $8.0 \%$ to $3.9 \%$ ) and hospitalization length (from 8.40 days to 5.26 days). Most of the observed improvements could be attributed to the increase in the utilization of P-PCI as the main reperfusion strategy.

\section{STEMI: A Hot Spot for Intervention}

Many studies have shown that patients with STEMI benefit from cardiovascular intervention more than other patients. Given the current controversy surrounding the role of PCI in stable ischemic heart disease even for symptom relief (10), P-PCI in patients with STEMI confers survival benefits even for patients older than 80 years. ${ }^{11,12}$ Thus, all statistics regarding these patients are of great import and any positive intervention that results in the improvement of care for these patients would directly affect cardiovascular mortality.

\section{Time Distribution}

There is currently a dearth of accurate information on the incidence of acute MI and specifically STEMI and the temporal trend thereof in the Iranian population. ${ }^{13,14}$ During the study period, 8,295 patients with STEMI were hospitalized in THC. The number of patients with STEMI showed an increase over these years; nonetheless, this upturn cannot be necessarily interpreted as a rise in the incidence or prevalence of STEMI because total admission in our center also exhibited an increase over this period. Apropos of STEMI occurrence, seasonal variation with a peak in winter and a nadir in summer ${ }^{15,16}$ and the circadian

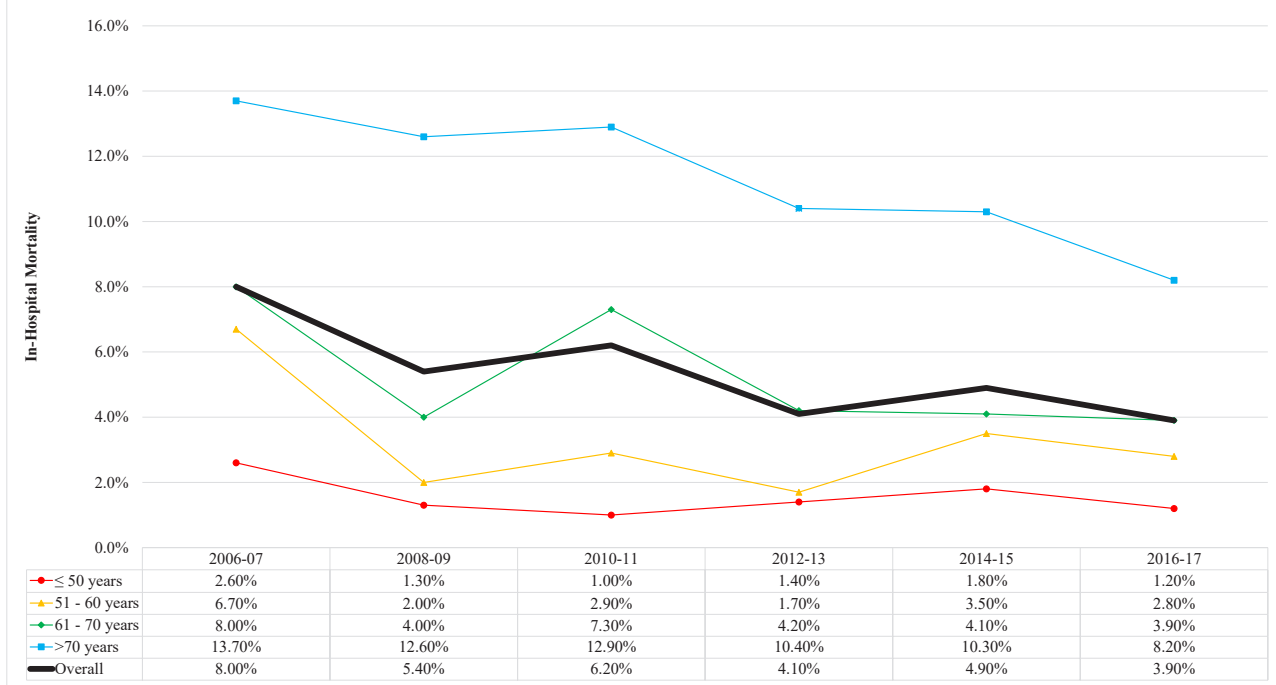

Figure 2. In-Hospital Mortality Trend of Patients with STEMI in Tehran Heart Center from 2006 to 2017 Based on Age. $P$ values for trends pertaining to various age categories: age $>70:<0.001$, age of 61-70: 0.042, age of 51-60: 0.037, age of $<50: 0.041$. P-value for the overall trend was also significant $(P<0.001)$. 


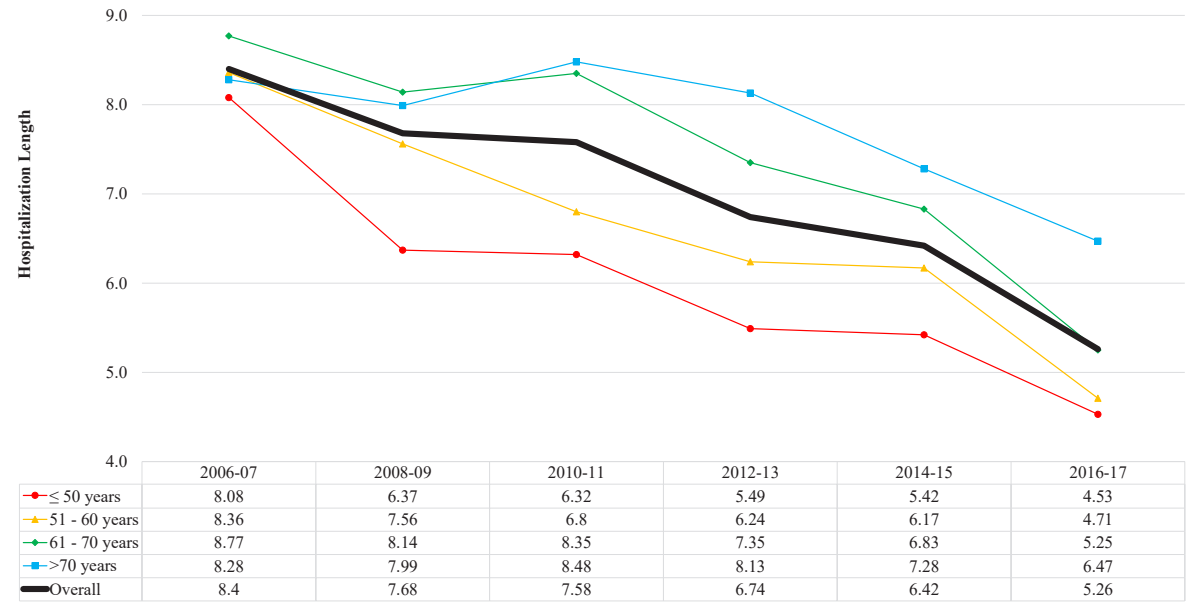

Figure 3. Mean Length of Hospitalization (in Days) Pertaining to Patients with STEMI in Tehran Heart Center from 2006 to 2017 Based on Age. A $5 \%$ trimmed mean was shown in this graph, which was substantially close to median values. All P-values for trends were $<0.001$.

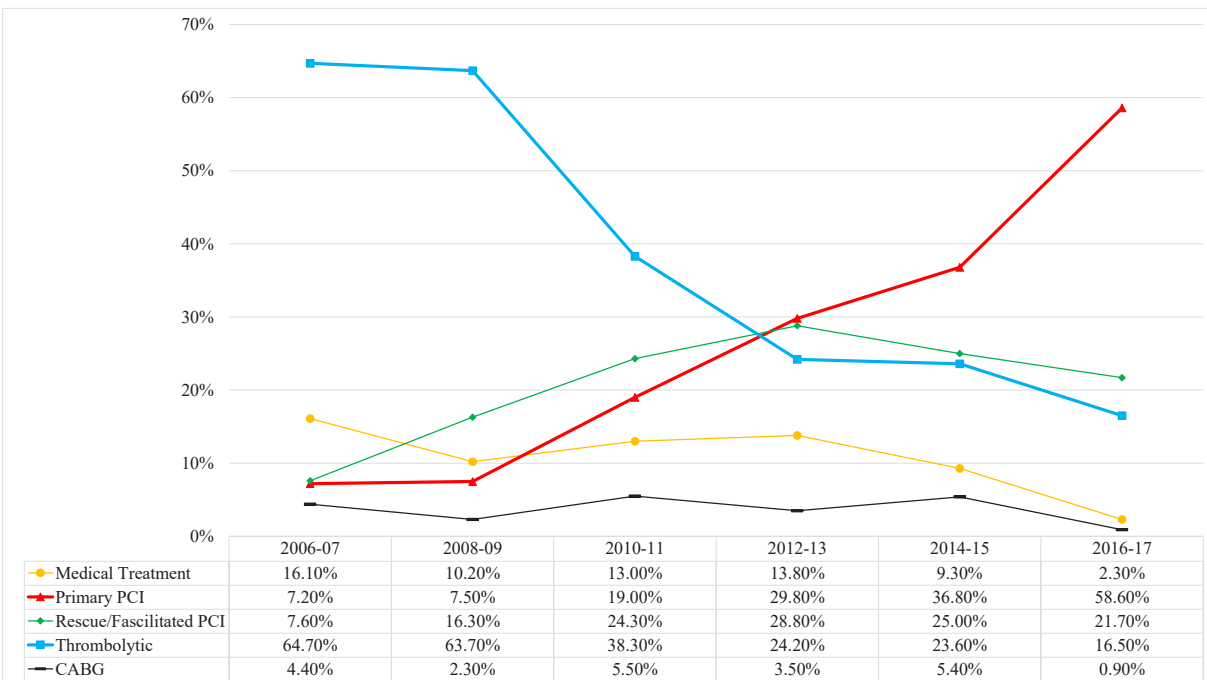

Figure 4. Different Treatment Strategies for Patients with STEMI in Tehran Heart Center from 2006 to 2017. Except for CABG $(P>0.05)$, all other $P$ values for trends were significant $(P<0.001)$. Abbreviation: $\mathrm{CABG}$, Coronary artery bypass graft; $\mathrm{PCl}$, Percutaneous coronary intervention.

rhythm with a morning peak have been propounded. Mogabgab et al reported a higher incidence of STEMI between 10 am and $2 \mathrm{pm}^{17}$ and Kanth et al reported $11 \mathrm{am}$ as the peak time for STEMI incidence. ${ }^{18}$ At first glance, our results appear to be completely similar to these studies inasmuch as most of our admissions occurred between $9 \mathrm{am}$ and $4 \mathrm{pm}$. It is worthy of note, nevertheless, that whereas the aforementioned studies reported the time of chest pain onset, we reported the time of arrival at the hospital. Considering a mean time period of 4 hours as a prehospital delay in Iranian patients with STEMI in the P-PCI era ${ }^{6}$ could be helpful to interpret this finding.

\section{Reperfusion Strategies}

Over these years, P-PCI has shown its efficacy, in comparison with pharmacologic thrombolysis, as the treatment of choice for patients with STEMI by reducing mortality, complications, ${ }^{19-21}$ and hospitalization length. ${ }^{22}$ P-PCI was a treatment strategy in THC even before the initiation of the 24/7 national program. In September 2015, under the aegis of the Iranian Ministry of Health and Medical Education, the 24/7 national program was launched to provide P-PCI 24/7 in designated hospitals. Currently, any patient with STEMI referring to THC at any hour and on any day is treated by P-PCI. A recent study reported a median of the-door-to-device time of 55 minutes (IQR: 40-82) in 2016, which was reduced to 46 minutes (IQR: $34-70$ ) in $2017 . .^{4}$ Once again, it is deserving of note that the rate of $16.5 \%$ for thrombolytic administration in our study represents patients initially treated in another center before referral to THC. 
Table 2. Multivariate Logistic Regression Analysis for the Prediction of In-Hospital Mortality and Prolonged Hospitalization

\begin{tabular}{|c|c|c|c|c|}
\hline & In-Hospital Mortality & \multirow{2}{*}{$p^{*}$} & Prolonged Hospitalization (> $5 \mathrm{~d}$ ) & \multirow{2}{*}{$\boldsymbol{P}^{*}$} \\
\hline & OR $(95 \% \mathrm{CI})$ & & OR $(95 \% \mathrm{Cl})$ & \\
\hline \multicolumn{5}{|l|}{ Treatment strategy } \\
\hline Medical treatment & Ref. & NA & Ref. & NA \\
\hline Primary $\mathrm{PCl}$ & $0.280(0.186-0.512)$ & $<0.001$ & $0.307(0.266-0.594)$ & $<0.001$ \\
\hline CABG & $0.482(0.220-0.903)$ & 0.025 & - & - \\
\hline $\mathrm{R} / \mathrm{F} \mathrm{PCl}$ & $0.420(0.071-0.812)$ & 0.001 & - & - \\
\hline Thrombolytic & $0.871(0.171-1.213)$ & 0.120 & - & - \\
\hline Age (per 1 year's increase) & $1.062(1.021-1.086)$ & $<0.001$ & $1.029(1.022-1.035)$ & $<0.001$ \\
\hline Gender (men vs. women) & $0.538(0.287-0.948)$ & 0.022 & $1.432(1.203-1.703)$ & $<0.001$ \\
\hline Opium use & $1.863(1.126-4.462)$ & 0.018 & $1.146(0.970-1.354)$ & 0.101 \\
\hline Diabetes mellitus & $2.611(1.508-4.910)$ & $<0.001$ & $1.365(1.174-1.588)$ & $<0.001$ \\
\hline Creatinine (per $0.1 \mathrm{mg} / \mathrm{dL}$ increase) & $1.363(1.125-1.812)$ & 0.002 & $1.239(1.021-1.502)$ & 0.030 \\
\hline Pulmonary edema & $6.085(1.043-8.071)$ & 0.002 & $2.013(0.793-13.823)$ & 0.173 \\
\hline VT/NF & $8.403(2.062-17.466)$ & $<0.001$ & $2.256(1.304-3.902)$ & 0.004 \\
\hline VSD & $3.316(1.280-6.711)$ & $<0.001$ & $1.156(0.686-7.179)$ & 0.181 \\
\hline
\end{tabular}

AV, Atrioventricular; CABG, Coronary artery bypass graft; CAD, Coronary artery disease; CHF, Congestive heart failure; CKD, Chronic kidney disease; COPD, Chronic obstructive pulmonary disease; OR, Odds ratio; PAD, Peripheral artery disease; PCI, Percutaneous coronary intervention; R/F, Rescue or facilitated; VSD, Ventricular septal defect; VT/VF, Ventricular tachycardia/fibrillation.

In addition to variables brought in the table, the multivariable model is also adjusted for hypertension, smoking, hyperlipidemia, prior angina, prior myocardial infarction, prior peripheral artery disease, prior stroke, left ventricular ejection fraction, underlying valvular disease, post infarction mitral regurgitation, post infarction atrial fibrillation, post infarction conductive block, and troponin level at the presentation. Only variables that showed a statistical significance with at least one of the outcomes of interest were brought in the table.

In-Hospital Mortality and Hospitalization Length

There are only a few reports regarding the in-hospital mortality of patients with STEMI in Iran. In a study conducted by Ghadimi et al in 2006, the in-hospital mortality rate was reported as high as $15.1 \%$ at Shariati Hospital, Tehran, Iran. ${ }^{23}$ A more recent study by Ahmadi et al., conducted in 2012 on the pooled data of 20,750 patients with STEMI from 31 provinces of Iran, showed a $12.1 \%$ rate of in-hospital mortality. ${ }^{24}$ With respect to in-hospital mortality among patients with STEMI in developed countries, rates of $5.1 \%$ in 2014 in Belgium and 5.5\% in 2016 in Switzerland were reported. ${ }^{25,26}$ With less than $5 \%$ in-hospital mortality in the past 6 years, the status of THC is more favorable than the rate in other hospitals of Iran and comparable with or even better than that in developed countries.

Hospitalization length has experienced a similar trend, as well. The length of hospital stay has garnered a great deal of attention in recent years, so that now, in tandem with the door-to-device time, the device-to-door time (which denotes hospitalization length) is deemed a measure of the quality control of hospitals. ${ }^{27}$ Research on the safety of early discharge of patients with STEMI has resulted in the inclusion of early discharge in guidelines. ${ }^{28-30}$ Regrettably, there is no report about STEMI and hospitalization length in Iran. In developed countries, the length of hospital stay was 6.5 days in Belgium in $2010^{31}$ and 7.2 days in the United States in 1995, which was lessened to 5.0 days in 2005. ${ }^{32}$ However, recent evidence showed a higher rate of adverse events in patients with STEMI discharged before 3 days, so the length of admission in the following years did not decrease further. ${ }^{33}$ Our result is comparable with these reports from developed countries.

Re-proof of the benefits of reperfusion strategies or adverse effects of previously well-studied variables associated with in-hospital mortality like age or mechanical complications of STEMI were not our main interest in this manuscript. However, the statistically significant association of opium abuse with in-hospital mortality in the multivariable-adjusted model, while smoking lost its significance, is quite interesting. A growing body of evidence recently shows both long-term and short-term increases in cardiovascular mortality related to opium consumption $^{34-37}$ that merits further consideration.

\section{Limitations}

Since the design of this research was retrospective and non-randomized, there were multiple limitations pertaining to potential missing data, the heterogeneity of baseline properties, and follow-up records. Furthermore, we encountered a considerable lack of accurate data regarding the records of the patients that were referred to THC from other medical centers. The short-term mortality and morbidity risk of CABG are substantially different from those of medical treatment or PCI. Another crucial problem is the impact of changing facilities, techniques, medications, protocols, patients' awareness and compliance, and treatment guidelines as well as the 
growing expertise of P-PCI operators over a long period.

\section{Conclusion}

In conclusion, from 2006 to 2017, a total of 8295 patients with STEMI were admitted into THC. Half of the admissions were recorded between 9 AM and 4 PM. Inhospital mortality and hospitalization length were almost halved in these years, and now P-PCI has completely replaced thrombolysis in the management of STEMI. A drastic rise in the use of P-PCI (from 7.2\% to 58.6\%) and a concomitant decline in fibrinolytic-based reperfusion (from $64.7 \%$ to $16.5 \%$ ) were eminent over this period. P-PCI, CABG, and even delayed PCI reduced mortality rates substantially when compared with medical treatment only. Still, the thrombolytic strategy was not associated with decreased in-hospital mortality after multiple adjustments. Further, P-PCI conferred remarkable protection against prolonged hospital stay. Indeed, the superiority of P-PCI over the other modalities lay in its ability to not only decrease short-term mortality but also to lower the likelihood of prolonged hospital stay.

\section{Authors' Contribution}

Study concept and design: SSe, GB, ON, SSa, GS, MSH, SM, PH. Acquisition, analysis, or interpretation of data: SSe, GS, GB, ON, MSH. Statistical analysis: SSe, GS, MSH. Drafting of the manuscript: SSe, GS, HK, GB, MSH. Critical revision of the manuscript for important intellectual content: SSe, GB, GS, SSa, ON, PH, SM, AM, $\mathrm{KSE}, \mathrm{AH}$.

\section{Conflict of Interest Disclosures}

The authors declare no conflict of interest.

\section{Ethical Statement}

This study was approved by the Tehran Heart Center Institutional Review Boards and all methods were performed in accordance to the guidelines. All patients were adult with active authorization and informed consent for use of their medical records for research.

\section{Acknowledgements}

We wish to thank all the staff of Tehran Heart Center, especially the Emergency Department and the Research Department, without whose contributions this work would not have been accomplished.

\section{References}

1. Saadat S, Yousefifard M, Asady H, Jafari AM, Fayaz M, Hosseini $M$. The most important causes of death in Iranian population; a Retrospective Cohort Study. Emerg (Tehran). 2015;3(1):16-21.

2. Abubakar I, Tillmann T, Banerjee A. Global, regional, and national age-sex specific all-cause and cause-specific mortality for 240 causes of death, 1990-2013: a systematic analysis for the Global Burden of Disease Study 2013. Lancet. 2015;385(9963):117-71. doi: 10.1016/S01406736(14)61682-2

3. Roe MT, Messenger JC, Weintraub WS, Cannon CP, Fonarow GC, Dai D, et al. Treatments, trends, and outcomes of acute myocardial infarction and percutaneous coronary intervention. J Am Coll Cardiol. 2010;56(4):254-63. doi: 10.1016/j.jacc.2010.05.008.

4. Salarifar M, Askari J, Saadat M, Geraiely B, Omid N, Poorhosseini $\mathrm{H}$, et al. Strategies to reduce the door-to-device time in st-elevation myocardial infarction patients. Tehran Heart Cent. 2019;14(1):18-27.

5. Abbasi M, Neishaboury M, Koohpayehzadeh J, Etemad K,
Meysamie A, Asgari F, et al. National prevalence of self-reported coronary heart disease and chronic stable angina pectoris: factor analysis of the underlying cardiometabolic risk factors in the fourth round of the SuRFNCD-2011. Global Heart. 2018;13(2):73-82.e1. doi: 10.1016/j.gheart.2018.01.001.

6. Poorhosseini H, Saadat M, Salarifar M, Mortazavi SH, Geraiely B. Pre-hospital delay and its contributing factors in patients with ST-elevation myocardial infarction; a cross sectional study. Arch Acad Emerg Med. 2019;7(1):e29.

7. Saadat N, Saadatagah S, Aghajani Nargesi A, Alidoosti M, Poorhosseini H, Amirzadegan A, et al. Short-term safety and long-term benefits of stent postdilation after primary percutaneous coronary intervention: Results of a cohort study. Catheter Cardiovasc Interv. 2020;95(7):1249-56. doi: 10.1002/ccd.28396.

8. Mensah GA, Hand MM, Antman EM, Ryan TJ Jr, Schriever R, Smith Jr SC. Development of systems of care for ST-elevation myocardial infarction patients: the patient and public perspective. Circulation. 2007;116(2):e33-8. doi: 10.1161/ CIRCULATIONAHA.107.184045.

9. Krumholz HM, Bradley EH, Nallamothu BK, Ting $\mathrm{HH}$, Batchelor WB, Kline-Rogers $\mathrm{E}$, et al. A campaign to improve the timeliness of primary percutaneous coronary intervention: Door-to-Balloon: An Alliance for Quality. JACC CardiovasC Interv. 2008;1(1):97-104. doi: 10.1016/j.jcin.2007.10.006.

10. Al-Lamee R, Thompson D, Dehbi H-M, Sen S, Tang K, Davies J, et al. Percutaneous coronary intervention in stable angina (ORBITA): a double-blind, randomised controlled trial. Lancet. 2018;391(10115):31-40. doi: 10.1016/S01406736(17)32714-9

11. Valente S, Lazzeri C, Salvadori C, Chiostri M, Giglioli C, Poli $\mathrm{S}$, et al. Effectiveness and safety of routine primary angioplasty in patients aged $\geq 85$ years with acute myocardial infarction. Circ J. 2008;72(1):67-70. doi: 10.1253/circj.72.67.

12. Guagliumi G, Stone GW, Cox DA, Stuckey T, Tcheng JE, Turco $M$, et al. Outcome in elderly patients undergoing primary coronary intervention for acute myocardial infarction: results from the Controlled Abciximab and Device Investigation to Lower Late Angioplasty Complications (CADILLAC) trial. Circulation. 2004;110(12):1598-604. doi: 10.1161/01. CIR.0000142862.98817.1F.

13. Khalili D, Sheikholeslami FH, Bakhtiyari M, Azizi F, Momenan AA, Hadaegh F. The incidence of coronary heart disease and the population attributable fraction of its risk factors in Tehran: a 10-year population-based cohort study. PLoS One. 2014;9(8):e105804. doi: 10.1371/journal.pone.0105804.

14. Mohseni J, Kazemi T, Maleki MH, Beydokhti H. A systematic review on the prevalence of acute myocardial infarction in Iran. Heart Views. 2017;18(4):125-132. doi: 10.4103/ HEARTVIEWS.HEARTVIEWS_71_17.

15. Swampillai J, Wijesinghe N, Sebastian C, Devlin GP. Seasonal variations in hospital admissions for ST-Elevation myocardial infarction in New Zealand. Cardiol Res. 2012;3(5):205-208. doi: $10.4021 / \mathrm{cr} 223 \mathrm{e}$.

16. Spencer FA, Goldberg RJ, Becker RC, Gore JM. Seasonal distribution of acute myocardial infarction in the second National Registry of Myocardial Infarction. J Am Coll Cardiol. 1998;31(6):1226-33. doi: 10.1016/s07351097(98)00098-9.

17. Mogabgab O, Wiviott SD, Antman EM, Foody JM, Wang TY, Sabatine MS, et al. Relation between time of symptom onset of ST-segment elevation myocardial infarction and patient baseline characteristics: from the national cardiovascular data registry. Clin Cardiol. 2013;36(4):222-7. doi: 10.1002/ clc. 12101 .

18. Kanth R, Ittaman S, Rezkalla S. Circadian patterns of ST elevation myocardial infarction in the new millennium. Clin Med Res. 2013;11(2):66-72. doi: 10.3121/cmr.2013.1120. 
19. Hosseiny AD, Moloi S, Atique S, Farshid A, Marley P. Mortality rate and cause of death following Primary Percutaneous Coronary Intervention (PPCl) for ST-segment elevation myocardial infarction (STEMI). Heart Lung Circ. 2015;24:S285.

20. Navarese EP, De Servi S, Politi A, Martinoni A, Musumeci G, Boschetti $\mathrm{E}$, et al. Impact of primary $\mathrm{PCl}$ volume on hospital mortality in STEMI patients: does time-to-presentation matter? J Thromb Thrombolysis. 2011;32(2):223-31. doi: 10.1007/ s11239-011-0598-1.

21. Jones BM, Kapadia SR, Smedira NG, Robich M, Tuzcu EM, Menon $\mathrm{V}$, et al. Ventricular septal rupture complicating acute myocardial infarction: a contemporary review. Eur Heart J. 2014;35(31):2060-8. doi: 10.1093/eurheartj/ehu248.

22. Stenestrand $U$, Lindbäck J, Wallentin L. Long-term outcome of primary percutaneous coronary intervention vs prehospital and in-hospital thrombolysis for patients with ST-elevation myocardial infarction. JAMA. 2006;296(14):1749-56. doi: 10.1001/jama.296.14.1749.

23. Ghadimi H, Bishehsari F, Allameh F, Bozorgi AH, Sodagari N, Karami N, et al. Clinical characteristics, hospital morbidity and mortality, and up to 1-year follow-up events of acute myocardial infarction patients: the first report from Iran. Coron Artery Dis. 2006;17(7):585-91. doi: 10.1097/01. mca.0000224419.29186.97.

24. Ahmadi A, Soori H, Mehrabi Y, Etemad K, Khaledifar A. Epidemiological pattern of myocardial infarction and modelling risk factors relevant to in-hospital mortality: the first results from the Iranian Myocardial Infarction Registry. Kardiol Pol. 2015;73(6):451-7. doi: 10.5603/KP.a2014.0230.

25. Gevaert SA, De Bacquer D, Evrard P, Convens C, Dubois P, Boland J, et al. Gender, TIMI risk score and in-hospital mortality in STEMI patients undergoing primary $\mathrm{PCl}$ : results from the Belgian STEMI registry. Eurolntervention. 2014;9(9):1095101. doi: 10.4244/EIJV9I9A184

26. Radovanovic D, Seifert B, Roffi M, Urban P, Rickli H, Pedrazzini G, et al. Gender differences in the decrease of in-hospital mortality in patients with acute myocardial infarction during the last 20 years in Switzerland. Open Heart. 2017;4(2):e000689. doi: 10.1136/openhrt-2017-000689.

27. Resnic FS, Shah SP. Balloon-to-door time: emerging evidence for shortening hospital stay after primary PCI for STEMI. J Am Coll Cardiol. 2015;65(12):1172-4. doi: 10.1016/j. jacc.2015.01.030.

28. Kotowycz MA, Cosman TL, Tartaglia C, Afzal R, Syal RP, Natarajan MK. Safety and feasibility of early hospital discharge in ST-segment elevation myocardial infarction-a prospective and randomized trial in low-risk primary percutaneous coronary intervention patients (the Safe-Depart Trial). Am Heart J. 2010;159(1):117.e1-6. doi: 10.1016/j. ahj.2009.10.024.

29. Grines CL, Marsalese DL, Brodie B, Griffin J, Donohue B, Costantini CR, et al. Safety and cost-effectiveness of early discharge after primary angioplasty in low risk patients with acute myocardial infarction. JAm Coll Cardiol. 1998;31(5):96772. doi: 10.1016/s0735-1097(98)00031-x.

30. Jirmár R, Widimský P, Capek J, Hlinomaz O, Groch L. Next day discharge after successful primary angioplasty for acute ST elevation myocardial infarction. Int Heart J. 2008;49(6):653-9. doi: 10.1536/ihj.49.653.

31. Claeys MJ, Sinnaeve PR, Convens C, Dubois P, Boland J, Vranckx $\mathrm{P}$, et al. Inter-hospital variation in length of hospital stay after ST-elevation myocardial infarction: results from the Belgian STEMI registry. Acta Cardiol. 2013;68(3):235-9. doi: 10.1080/ac.68.3.2983416.

32. Saczynski JS, Lessard D, Spencer FA, Gurwitz JH, Gore JM, Yarzebski J, et al. Declining length of stay for patients hospitalized with AMI: impact on mortality and readmissions. Am J Med. 2010;123(11):1007-15. doi: 10.1016/j. amjmed.2010.05.018.

33. Swaminathan RV, Rao SV, McCoy LA, Kim LK, Minutello RM, Wong SC, et al. Hospital length of stay and clinical outcomes in older STEMI patients after primary $\mathrm{PCl}$ : a report from the National Cardiovascular Data Registry. J Am Coll Cardiol. 2015;65(12):1161-1171. doi: 10.1016/j. jacc.2015.01.028

34. Shavazi MT, Saadatagah S, Aghajani H, Poorhosseini $H$, Salarifar M, Amirzadegan A, et al. Does Invasive Treatment Increase the Long-term Survival of ST-Elevation Myocardial Infarction Patients with a History of Coronary Artery Bypass Graft Surgery? J Tehran Heart Cent. 2019;14(3):109-120.

35. Hosseini SK, Masoudkabir F, Vasheghani-Farahani A, AlipourParsa S, Fathollahi MS, Rahimi-Foroushani A, et al. Opium consumption and coronary atherosclerosis in diabetic patients: a propensity score-matched study. Planta Med. 2011;77(17):1870-5. doi: 10.1055/s-0031-1280017.

36. Masoudkabir F, Sarrafzadegan N, Eisenberg MJJNrC. Effects of opium consumption on cardiometabolic diseases. Nat Rev Cardiol. 2013;10(12):733-40. doi: 10.1038/ nrcardio.2013.159.

37. Ziaee M, Hajizadeh R, Khorrami A, Sepehrvand N, Momtaz S, Ghaffari SJIJoPH. Cardiovascular Complications of Chronic Opium Consumption: A Narrative Review Article. Iran J Public Health. 2019;48(12):2154-64 